\title{
Protecting the Value of Interdisciplinary Collaborations in the Development of a New Budget Model
}

\author{
Carl Lejuez, Interim Provost/Executive Vice Chancellor \\ University of Kansas
}

here is a saying that if you want to know what an administrator cares about, do
not listen to what they say are priorities. Instead, look at their budget and where
they allocate resources.

The new budget model for the Lawrence campus of the University of Kansas (KU) was developed as part of a larger effort to build a more stable and fiscally healthy KU, where priorities and budgetary decisions tell the same story.

For as far back as anyone can remember, KU utilized a historical/incremental budget model that provides the same allocation to units annually. While this model provides relative certainty about available funding each year, it also limits new and higher-risk efforts and relies on the use of special arrangements to provide units trying new things with the funds needed for those efforts. Such arrangements always make sense in the moment but over time can become convoluted and have unpredictable and unintended consequences for the unit in question as well as for the overall budget of the university.

KU's traditional budget model also has limited the ability to prioritize interdisciplinary collaborations because these efforts can often require considerable resources and the traditional model does not allow for incentivizing/rewarding these efforts when they are successful. Such collaborations are important for a number of reasons: they broaden perspectives on research problems, strengthen research capabilities and productivity, allow for cost efficiencies, improve research opportunities for students, expand the ability to establish external partnerships, and create important relationships among faculty. New budget models that are revenue-driven are often thought to undermine collaboration because there is a belief that units would rather go it alone and would not want to work together and share in the benefits of strong collaboration.

Since April 2018, our leadership team, in close collaboration with the KU community, has been working to redesign KU's budget model for revenue allocation. A Responsibility-Centered Management (RCM) model, or a hybrid of it, has been adopted in increasing numbers among higher education institutions around the country. The RCM model offers decentralized budget authority where a percentage of revenue is controlled by the unit that generated that revenue. In a full RCM, this amount is $100 \%$ of the revenue generated, but the academic unit also must cover all of its costs, including its facilities and services, from support units such as the libraries. The academic unit would also cover the expenses of strategic priorities and other unit-generated initiatives. Hybrid models return less than $100 \%$ and provide additional budget based on historic allocations and/or central priorities aligned with academic units. In some hybrid models, academic units receive fewer funds from central administration but are not required to pay some and/or all of its service costs. 
Our new model has many aspects of an RCM but funds service units separately and provides resources to the academic units based on a proportion of revenue generated as well as outcomes in centrally determined priority areas. Given the latter, we refer to our hybrid RCM as a Priorities-Centered Management (PCM) model. This approach intentionally and explicitly aligns our budget with our priorities, including research; undergraduate and graduate student success; the career development of our people; outreach across our state and beyond; and diversity, equity, and inclusion. It orders allocation in a meaningful manner across (1) foundational priorities, (2) institutional strategic priorities, and (3) unit allocations.

In May 2018, the Lawrence campus of KU (referred to throughout simply as "KU") underwent a \$20 million base budget reduction for FY2019, which coincided with the start of efforts to create a new budget allocation model for our campus. To ensure the Lawrence campus community was educated about the rationale for a new budget model and the specifics of the model proposed, we held a series of seven town halls that were livestreamed and provided details on how the new model will better align resource allocations with strategic priorities. We presented information about university-level strategic investments, the way funding is distributed to academic units and academic service units, and funding foundational priorities such as merit-pay increases, building maintenance, and financial reserves. Participants had opportunities to ask questions and voice any concerns, thus contributing to the ultimate design of the model.

Significant budget review and revision work took place during the 2019 fiscal year by a working group in consul- tation with campus leadership. The working group developed and shared guiding principles that would help shape the development of the new budget model:

1. Common Good: We have a responsibility to focus on the greater good of the entire university rather than our individual units. The common good includes what is best for our students, academic excellence, and the overall health and sustainability of the university.

2. Transparency: As we go through the process of developing a new budget model, there will be the broadest possible participation, sharing of decisions, and next steps. Diversity of viewpoints is encouraged and accepted. Constant and direct communication occurs so all stakeholders are thoroughly informed about the new budget model processes and issues.

3. Clarity: Simplicity is preferred over complexity.

4. Innovation: While appreciating what is positive about prior budget models and approaches, we will encourage innovative planning to adapt to the current environment.

5. Responsiveness: We remain cognizant of the changing environment and design toward nimbleness to respond to future campus changes.

6. Respect (for each other and the product): The budget model will be a result of the investment and input from the entire leadership team and their consideration of feedback solicited from constituencies across campus. 
The working group met roughly every week during the 2019 fiscal year with the aim to identify:

- a high-level structure of allocation

- formula for determining fund allocations for academic units and academic service units, and an order of operations that ensures the ability of leadership to plan

- general criteria of incentivized activities

- means of evaluating progress toward unit and institutional goals (incentivized activities)

- mechanisms for reducing extreme swings in fund allocation

- a calendar for implementing the new budget model, evaluating unit performance, and determining future allocations

Throughout the year, direct reports to the provost, including deans, vice provosts, and other high-level directors, met on a weekly basis to discuss the development of the model. The provost also held regular town hall presentations of model progress and held hundreds of individual and small-group meetings of faculty, staff, and students from across campus. These meetings included participant feedback and insight that led to many important changes and a stronger overall model. The resulting PCM model will allow the university to save and invest in priorities and better support program innovation geared toward advances in strategic priorities.

Institutional Overview: The 1-2-3 of the New Budget Allocation Model

The first structural feature of the model is the creation of three broad categories in which budgetary resources can be allocated. The source of these funds is state appropriations, tuition revenue, and certain other operating revenues.
Other funding streams, such as course fees, differential tuition, and fee charges for services, will be allocated directly to the appropriate unit and are not part of this budget allocation model or the pool of funds being distributed. KU Endowment funds available to various campus offices are also separate from the budget model.

- Step 1: Funding for Foundational Priorities. The chancellor and provost will capture a limited pool of funds from state appropriations and tuition revenue. Funds will be used to support centralfoundational-priorities, such as restoration of savings/reserves and contingency funds, regular merit raises, deferred maintenance needs, and increased yearto-year mandatory costs (external licensing, subscriptions, etc.).

- Step 2: Funding for Institutional Strategic Priorities. Strategic priorities are areas that are part of KU's vision, future goals, and growth. The funds are held by the chancellor and the provost and are expected to be used for onetime or limited-term investments that can build reputation or revenue opportunities. These may also be used to support initiatives determined through the strategic planning process and will largely take the place of "Provost Commitments" currently made throughout the school year on a case-by-case basis. Some Provost Commitments will still be made as needed but shifting funds to a more strategic approach helps ensure more vision-aligned investments.

- Step 3: Determination of Allocations to Units. This distribution 
will provide resources needed by each academic unit (the schools and the College) and academic support units that provide crucial services to students, faculty, and staff. The pool for allocation is approximately $\$ 420$ million. In Year One, roughly 51 percent of remaining funds will be allocated to academic units and 49 percent will be allocated to academic support units.

The new budget model, represented in the graph below, will take effect in Fiscal Year 2021 and will be based on performance in Calendar Year 2019. This will allow us time to obtain metrics beyond student credit hours. Once we have all of the necessary data, we will seek to balance investment in foundational priorities and allocation to units with strategic investments where possible. Evaluating the success of our new budget model requires that its structure and its results are clear and easy to understand.

\section{Academic Unit Allocations}

As noted above, remaining budget is largely split evenly across the academic (the College of Liberal Arts \& Sciences and each of the professional schools) and support units. For academic units, funding will be distributed based on performance across a set of key priority areas. Where possible, performance will be centrally determined, but in some cases a centrally generated score is less possible/ meaningful (e.g., research products and faculty development). In those cases, performance will be peer-reviewed by other deans the provost's leadership team with the provost assigning a final score. Percentages of budget allocation assigned for each key priority area are provided below.

University Operating Budget

\section{Tuition \& Other Operating Revenues}

State Appropriations

Centrally Held Funds for Strategic Priorities

Step 1: Foundational Priorities

Merit • Deferred Maintenance $\bullet$ Reserves and Contingency $\bullet$ Mandatory Costs

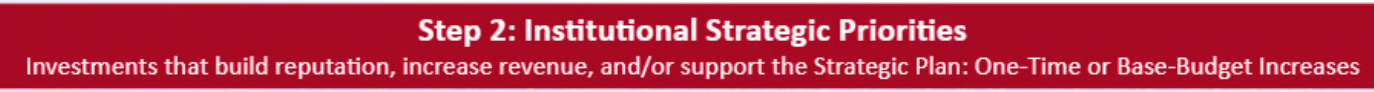

Unit Allocations

$51 \%$ of the university budget will be allocated to Academic Units and $49 \%$ to Academic Support Units

Step 3: Academic Units

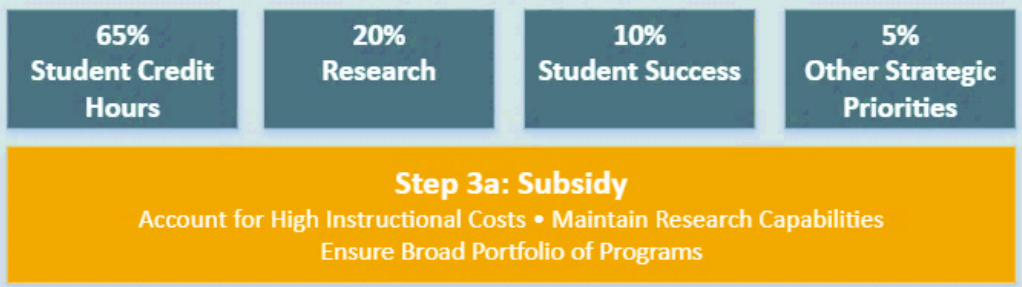

Step 3b: Implementation Guardrails

Reduce impact of budget fluctuations due to model implementation. Gains/Losses held to: FY21: $1 \% \cdot$ FY22: $2 \% \bullet$ FY23: $2 \% \bullet$ Reevaluated every 3 years
Step 3: Support Units

$100 \%$

Benchmarked

Cost Drivers

$+/-X \%$

Performance

Related to

Mission 
- Student Credit Hours - 65\%

o For undergraduate units, $75 \%$ of SCH will be assigned to the instruction unit and 25\% to the major. Students with more than one major count for both units.

o For graduate units, $\mathrm{SCH}$ are weighted at $2 x$ to support the higher cost of instruction. Graduate $\mathrm{SCH}$ is defined by the level of the student, not the course number. As with the undergraduate allocation, $75 \%$ is assigned to the instruction unit and $25 \%$ to the major.

- Research - 20\%

o Research Grants/Contracts (external direct/indirect costs), $10 \%$

o Grant Efforts/Success (faculty submitting external proposals and/or faculty with active external awards), $2 \%$

o Research Products (journal articles, books, chapters, creative/scholarly/legal works, invention disclosures/patents issued), $4 \%$

o Research Impact (awards/ recognition, citations, invited presentations, editorships, national/disciplinary ranking, societal and economic impact), $4 \%$

- Student Success - 10\%

o Graduation Rates (degrees awarded), 2.5\%

o Time to Degree (time from junior level), $2.5 \%$

o Student Experience at KU (participation in high-impact experience) , $1.66 \%$

o Placement Post-KU (placement rates, career counseling), $1.66 \%$ o Teaching and Mentoring Quality (pedagogical advances, awards to faculty-staff, assessment of teaching, advising, classroom focus, bottleneck courses), $1.66 \%$

- Other Strategic Initiatives - 5\%

o Climate and Support (diversity, equity, and inclusion; faculty/staff development), $2.5 \%$

o Collaboration and Outreach (internal, local, and global; fundraising and alumni engagement; efficiency), $2.5 \%$

In addition to the budgeting approach for the academic units provided above, several other budgeting strategies are notable:

Subsidy. In some cases, certain academic units may receive a subsidy outside of the $\mathrm{SCH}$ unit allocation process. Such subsidies recognize a variation in instructional costs or may, at the provost's discretion, ensure a broad portfolio of disciplines, preserve foundational areas that aren't well suited to the budget models, and/or maintain research capabilities in high-potential areas. The funding methodology for subsidies is to set aside an initial \$20 million from unit allocation to the academic units. Units cannot receive a subsidy greater than $100 \%$ of its prior-year budget, and units with growth greater than $10 \%$ are capped and the difference is added back to the subsidy pool.

Implementation Guardrails. The budget model includes guardrails, a strategy to reduce the impact of budget fluctuations that could occur with implementation of the model. The strategy states that no school or the College will experience gains or losses greater than the percentages outlined below each year (as compared to the prior year): 
- FY20: Historical Base Budget (0\% guardrails)

- FY21: 1\% guardrails

- FY22: 2\% guardrails

- FY23: 2\% guardrails

- FY24 \& beyond: Continuation and/or \% of guardrails reevaluated every 3 years

\section{Academic Service Unit Allocations}

Service unit allocations will be funded $100 \%$ based on service responsibilities, benchmarked to peers on cost drivers. They will reflect three to ten responsibilities that support the mission of $\mathrm{KU}$ and convey the goal and activities of each unit. Service units can be allocated additional funding based on their performance in meeting service responsibilities. Similar to the academic units, service units also will have a set of guardrails in place. ness that interdisciplinary initiatives are most likely to bring teaching innovation, research impact, and the development of new external resources. These collaborations also support key components of the model that directly reward interdisciplinary work including collaboration, outreach, and efficient use of funds, as well as research impact, expenditures, and pedagogical advancements, all of which benefit from interdisciplinary efforts.

The University of Kansas recognizes that successful grant awards are essential to a robust research enterprise, and interdisciplinary relationships are key to that success. Not only are grant dollars greater and increasingly more available at the intersection of disciplines, there are benefits that extend beyond dollars. In an era of heightened competition for scarce

\section{Graphic of Service Unit Allocation}

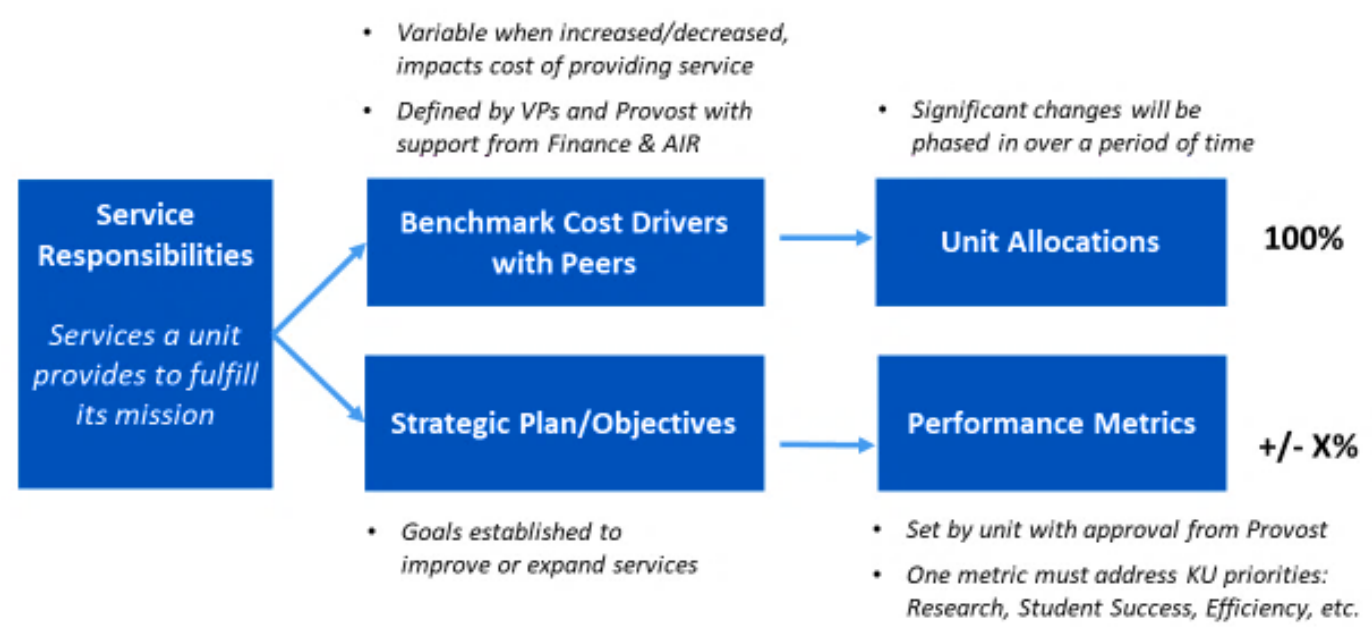

PCM Budget Model Support for Interdisciplinary Collaborations

Flexibility in funding strategic priorities can make it possible to provide increased support for interdisciplinary collaborations. This begins with Step 2 of the model that supports strategic initiatives at a time when there is great aware- resources, higher education must continually seek ways to collaborate, share data where possible, and bring needed perspective to the problems that research seeks to address.

For more information, please visit http://provost.ku.edu/budget-model-redesign. 